\title{
Artigo
}

\section{QUERENÇA: CONSTRUÇÃO DE UMA CENA AFRO-BRASILEIRA}

\author{
QUERENÇA: AFRO-BRAZILIAN \\ SCENE CONSTRUCTION \\ QUERENÇA: ESCENA AFROBRASILEÑA \\ EN CONSTRUCCIÓN
}

Vanessa S. Soares

Vanessa S. Soares

Arte-educadora licenciada em Teatro. Mestranda em Educação - Movimentos Sociais pela Ufscar - Sorocaba. 


\section{Resumo}

Este artigo trata de Querença, vivência cênica realizada pelo Grupo Saramuná, inspirada nas reminiscências acerca da religiosidade afro-brasileira presente nas manifestações populares. Esta pesquisa foi desenvolvida pela autora usando como metodologia o laboratório de criação "Ancestralidade - Matrizes - Cena Afro-brasileira", com a finalidade de colocar em questão os desdobramentos da cultura tradicional em diálogo com as artes da cena, na perspectiva de construção de uma cena afro-brasileira fundamentada, cuja estrutura baseia-se na compreensão da memória ancestral e nas suas correlações com o religioso e o sagrado, as artes cênicas e a educação. Conclui-se que é importante para a artista negra fazer vibrar o potencial da participação e pertencimento que as culturas de matriz africana possibilitam.

Palavras-chave: Manifestação afro-brasileira, Mulher negra, Religiosidade, Teatro.

\section{Abstract}

This article deals with Querença, a scenic experience by the Saramuná Group, inspired by the Afro-Brazilian religion reminiscences present in popular manifestations. This research was developed by the author using as methodology the workshop "Ancestralidade - Matrizes Cena Afro-brasileira," with the purpose of questioning the unfolding of the traditional culture related with the arts of the scene, aiming to build a grounded Afro-Brazilian scene, whose structure is based on the understanding of the ancestral memory and its correlations with the religious and the sacred, the performing arts and education. The conclusion is that it is important for the black artist to move the participation and belonging potential that African matrix cultures make possible.

Keywords: Afro-brazilian manifestation, Black woman, Religiosity, Theater. 


\section{Resumen}

Este texto trata de Querença, escenificación realizada por el grupo Saramuná, inspirada en las reminiscencias acerca de la religiosidad afrobrasileña presente en las manifestaciones populares. Esta investigación fue desarrollada por la autora con la metodología de trabajo el laboratorio de creación Ancestralidade - Matrizes - Cena Afro-brasileira, con el fin de poner en discusión los despliegues de la cultura tradicional en diálogo con las artes de la escena, en la perspectiva de construir una escena afrobrasileña, sostenida en la memoria ancestral y sus correlaciones entre lo religioso, lo sagrado, las artes escénicas y la educación. Se concluye que es importante para la artista negra hacer vibrar el potencial de participación y pertenencia que posibilitan las culturas de matriz africana.

Palabras clave: Manifestación afrobrasileña, Mujer negra, Religiosidad, Teatro.

É na fé que o ser humano vê refletido seus sonhos. É na bênção do sagrado que ele encontra forças para ser, assim, só ser mesmo, como se o existir fosse presente divino, mesmo na vida castigada com carmas, penas e sinas. Este artigo trata da Querença, uma vivência cênica realizada em Sorocaba/SP no ano de 2015 pelo Grupo Saramuná, pautada nas memórias, nas alegrias e nos infortúnios da vida do ser humano, das marcas de dor de um povo sofrido pelas chibatadas e o seu legado de resistência e persistência que a lei da sobrevivência inspira e obriga em perpetuar. A fé na vida, louvada com cantos, danças e batuques em agradecimento àqueles que, nos céus, louvam por nós, apesar dos pesares. A Querença - benquerença, crença... - tece colchas de retalhos de histórias, que possam fazer sentido, justificar, afirmar ou contradizer a possível estância do devir da vida.

Yabá, anciã de um terreiro assolado por mazelas advindas de todas as dificuldades da vida, sob a perspectiva sócio-histórica brasileira, trazendo as sequelas de um território construído sob o sistema escravocrata, é a personagem-guia desse experimento cênico. Perde um filho e, defronte a dor que avassala sua existência feminina e materna, só encontra força na crença de que tudo o que passamos é sina. E na caminhada das dores não se sustenta 
sozinha, o sagrado, o divino se fazem presentes na "força forçada" em ter que seguir com a vida. É na amizade com São Benedito, o santo dos pretos, que Yabá, em meio a descobertas lúcidas sobre a vida e sobre as memórias um pouco endoidecidas pelo tempo, conta ao público sobre sua vida, seu povo, suas histórias, lutas e honras. Todo esse enredo sendo abarcado pela simbologia viva e presente na Manifestação Popular Afro-brasileira Tambor de Crioula, a qual propõe apenas um espaço-tempo de experiência.

Não há uma definição assertiva sobre o que é essa vivência, e sim uma proposta coesa no seu desenvolver. É teatro, é dança, é música, é performance, é manifestação popular, é ato religioso, é vida que se vive, sem paradigmas na ação efêmera e profunda das artes cênicas. Trataremos aqui como vivência cênica, uma vez também que o público faz parte diretamente deste momento como sujeito, sendo proposta, em seu processo de fruição, uma participação ativa, de quem recebe e devolve sensações, reflexões e percepções do que acontece ali. No momento em que se vive, ele toma decisões sobre o seu percurso e, assim, altera e transforma suas relações com a arte no momento presente, circundando, inclusive, uma dúvida se aquilo que está acontecendo "é de verdade ou não?". Esta é uma vivência cênica decorrente de estudos e pesquisas voltados às práticas tradicionais da cultura popular afro-brasileira trazidas, para a cena espetacular, individualmente pela atriz (autora do artigo) ou de forma coletiva, pelos atuantes do Grupo Saramuná, por meio de um processo construído sob o fazer e sob as reflexões advindas desse processo. Tal grupo é formado por não artistas, participantes das oficinas formativas que contemplavam este projeto e que se integraram ao grupo - corroborando e fazendo parte do processo de criação e construção deste trabalho, que teve também a colaboração do Mestre Tião Carvalho, maranhense radicado em São Paulo, artista negro, mestre de culturas tradicionais, ator, músico, cantor e pesquisador das artes e culturas afro-brasileiras.

Tratamos aqui de comunidades negras remanescentes da época escravocrata brasileira, negros escravizados líderes de quilombos e resistentes à escravidão, que foi tão assombrosa e cruel em solo brasileiro. Tratamos de saberes de mestres e líderes de comunidade que trazem anos (séculos)

1. Cacofonia usada para melhor exprimir essa imagem. 
de resistência, lutas, manutenção e permanência de sua identidade, que representam a força de seus antepassados que serve como base para seus legados. Mas ainda assim, com tanta força e potência no existir, essas manifestações são histórica, cultural, religiosa e socialmente subjugadas pela lógica hierárquica e racista da nossa sociedade, cujos valores privilegiados são os ocidentais, cristãos, brancos e masculinos.

No decorrer do processo histórico brasileiro, os homens e mulheres negras sempre lutaram e resistiram bravamente a toda forma de opressão e discriminação. Eles forjaram formas elaboradas de lidar com a vida, com o corpo, assim como expressões musicais múltiplas. Construíram uma estética corporal que está impregnada na cultura do povo brasileiro. Por meio da resistência política, da religião, da arte, da música, da dança e da sensibilidade para com a ecologia o negro produz, participa e vivencia a cultura afro-brasileira. (MUNANGA; GOMES, 2004)

Cada comunidade que resiste ao tempo e ao sistema hegemônico que quer aniquilá-las é um ato político e transgressor, podemos dizer um ato de rebeldia de não se permitir e não se deixar persuadir pelo discurso invasivo, opressor e preconceituoso. E é por isso que se faz necessário conhecê-las intimamente tanto quanto possível para aprender e multiplicar as ciências e saberes ancestrais fundamentais para o desenvolvimento humano em sociedade e para a construção do ser. Pois bem, pensando numa valorização e difusão de práticas tradicionais de matriz africana para além de seus espaços originários, pergunta-se: como se estabelece a transmissão do saber das tradições populares nas comunidades e grupos sociais que se praticam tais manifestações? E como promover um processo de construção de uma identidade étnico-cultural acerca das reminiscências culturais afro-brasileiras para além das comunidades, neste caso num processo artístico, vivendo em um ambiente que, sistematicamente, se nega a valorizar as contribuições trazidas pelo povo da África à nossa cultura?

A manutenção dos movimentos afro-brasileiros surge como uma medida não só de não permitir o esquecimento do que se preserva, mas na urgência em estender esses saberes tradicionais a novos interessados, como uma necessidade de permanência e sobrevivência de uma cultura que vive na iminência de se colapsar por falta de valorização e continuidade. 
A escolha de trabalhar as manifestações populares na cena deve-se ao fato de portarem variados aspectos: coreográficos, visuais, formas de cantos, dramatizações e simbologias na sua organização e manutenção. Além disso, trazem em seu bojo elementos referentes à formação histórica, econômica, política e social brasileira, questões de extrema importância a serem discutidas, principalmente no atual contexto político do país. A função da arte é criar consciência, uma consciência de si, do outro, uma consciência do mundo, "não necessariamente verbal ou verbalizável, sistematizável" (BOAL, 2001, p. 33), considerando-se as diversas formas de organização das coisas empreendidas pela arte, que não somente usa palavras, mas movimentos, gestos, cores, sons, ações humanas, objetos, simbologias, no tempo e no espaço, uma vez que a "comunicação estética é a comunicação sensorial e não apenas racional” (BOAL, 1996, p. 13), sendo ela múltipla e não única como a própria cultura. Na educação popular, os processos de transmissão de saber nessas comunidades e grupos tornam-se imprescindíveis para a formação do ser consciente do seu espaço geográfico e do seu território cultural, ressaltando a importância de se estabelecer pontes entre as experiências de participação nos campos da arte e da educação. No prefácio da Pedagogia do Oprimido, encontramos paralelo com a questão dos processos conscientizadores e humanizadores:

Não têm a ingenuidade de supor que a educação só ela decidirá os rumos da história, mas têm, contudo, coragem suficiente para afirmar que a educação verdadeira conscientiza as contradições do mundo humano, sejam estruturais, superestruturais ou interestruturais, contradições que impelem o homem a ir adiante. As contradições conscientizadas não lhe darão mais descanso, tornam insuportável a acomodação. Um método pedagógico de conscientização alcança as últimas fronteiras do humano. $E$ como o homem sempre se excede, o método também o acompanha. É a educação como prática de liberdade. (FREIRE, 1994, p. 29)

Faz-se necessário romper os estigmas da suposta inferioridade negra e a supremacia branca, que foi propagada como forma de justificar a escravidão do negro. Tal estratégia resultou na construção de uma imagem condenada e desumanizada do negro, o negro como objeto coisificado, não como sujeito de si, de sua história e de seus caminhos. A sensação de não pertencimento 
à categoria humana traz efeitos nefastos para a construção de sua autoimagem. Há uma dívida social para com o negro e é preciso reparação em todas as instâncias do coletivo. Neste trabalho, o caminho da conscientização pela educação afetiva por meio da arte desenha novos devires para a ascendência afro-brasileira para/com/pelo sujeito, senhor de sua história, sua palavra, sua narrativa. A constituição dessa autoimagem se dá a partir da relação com o outro e com o mundo, uma vez que o homem é de natureza social e sua práxis se dá na realidade concreta de suas relações. Considerando que vivemos em um meio contaminado por valores, é evidente que a criança negra irá constituir sua autoimagem a partir desses códigos de valores socialmente estabelecidos. Para tanto, a importância em reconhecer os valores culturais herdados da memória africana para consolidar uma identidade étnico-cultural brasileira é indispensável para a construção do ser negro, como sujeito de suas manifestações e de suas histórias. A cultura popular é um dos caminhos mais plausíveis de mudança e transformação dessa perspectiva, seja pela organização ontológica de suas tradições, seja pelas manifestações de seus saberes por meio da música, da dança, da poesia, das artes visuais, da história etc., e é na luta em resistir aos preconceitos que o negro se reconhece, que faz ponte intelectual e espiritual com seus ancestrais e, assim, torna-se consciente do papel importante da memória, da tradição e da permanência, preocupando-se em endossar a transmissão de saberes, a divulgação e a continuidade de uma tradição que não deve se solidificar no passado, mas seguir rumo às novas gerações e aos novos espaços, legitimando a identidade brasileira. Sobre isso, Munanga e Gomes (2004, p. 152) fazem um apontamento importante:

De uma ponta a outra do continente americano e do Brasil a população negra utilizou o corpo como instrumento de resistência sociocultural e como agente emancipador da escravidão. Seja pela religiosidade, pela dança, pela luta, pela expressão, a via corporal foi o percurso adotado para combate, resistência e construção da identidade.

Pensando em intervir intencionalmente, promovendo a desconstrução de processos desumanizadores e opressores, é que o processo artístico se dá em diálogo direto com essas manifestações e comunidades tradicionais. 
A questão aqui está em mudar a perspectiva do olhar para a denúncia pela poesia e para as reminiscências culturais, como fatores positivos desse processo histórico doente. Para o trabalho cênico, havia uma preocupação em sistematizar essas discussões, horizontalizar e expandir a pesquisa do corpo afro-brasileiro e seus ritos em cena. $\mathrm{E}$ o desdobramento desse processo de pesquisa se deu com a vivência cênica Querença, uma vivência-espetáculo como tentativa de desvendamento de um dos aspectos da cultura popular brasileira, a fé, tendo a manifestação popular Tambor de Crioula ${ }^{2}$ e todos os temas que a circunda como assunto e inspiração para a criação cênica.

A manifestação do Tambor de Crioula é tratada neste trabalho como legado, transmissão de saber dos antigos mestres às novas gerações, e Querença é a possibilidade de ressignificar essas reminiscências sob a perspectiva da arte cênica. Retratar em cena o universo poético da religiosidade afro-brasileira é dar voz aos diversos avôs e avós griôs ${ }^{3}$ presentes no imaginário popular, estes que foram escravizados, estes nossos antepassados que hoje, neste tempo, são a representação dos saberes. Gente brasileira simples, sabida da vida e crente na melhora da sua lida. Querença tem, então, a possibilidade de discutir artisticamente e divulgar um posicionamento crítico de resistência e ascendência da cultura afro-brasileira. O Tambor de Crioula foi escolhido por tratar de aspectos relativos às reminiscências culturais afro-brasileiras não só na temática, mas na história, fundamento e resistência desse folguedo. É uma manifestação afro-brasileira herdada dos escravizados, na qual se utiliza o canto, a dança e a percussão para realizar seus rituais de "benquerença" aos seus santos de proteção. Uma roda de Tambor de Crioula se dava sempre quando alguém ou um grupo necessitava da bênção do santo, seja no cumprimento de uma promessa, ou agrado para fazer um pedido, ou até mesmo num funeral, na despedida de um ente querido. O santo mais popular nas manifestações afro-brasileiras é São Benedito e Nossa Senhora do Rosário, por serem considerados “os santos dos pretos", e é principalmente a São Benedito que se dedica a realização deste folguedo, marcando a relação

2. Tambor de Crioula é uma dança de matriz africana praticada por descendentes de escravos africanos no estado brasileiro do Maranhão, em louvor a São Benedito, um dos santos mais populares entre os negros.

3. Griô é um termo utilizado na cultura africana, para denominar os contadores de histórias, geralmente mais velhos, considerados conhecedores dos saberes e do axé da vida. 
sincrética da religiosidade brasileira. Nos dias de hoje, não é preciso data certa, ou momento específico, os brincantes têm a liberdade de boiar ${ }^{4}$ sempre que acharem necessário, comandados pela cabeça ou pelo coração. Essa é uma manifestação bastante intensa e a união da comunidade que a pratica é bastante acentuada, pois necessita de uma organização sistemática para realizar o folguedo, são muitos elementos e muitas etapas para se fazer a roda: é preciso acender a fogueira para afinar os tambores, é preciso preparar o altar para o "São", é preciso reunir os brincantes, é preciso pensar na comida para todos e, de ordem prática do fazer da roda, ela requer força para tocar os tambores e resistência física para dançar os trupés característicos da dança. $\mathrm{Na}$ roda, tradicionalmente, só os homens tocam e só as mulheres dançam, por isso também é considerada uma dança feminina, na qual a mulher demonstra e representa todo seu trejeito de sensualidade e feminilidade; sendo o, bastante teatral, jogo da punga ${ }^{5}$ entre as coreiras ${ }^{67}$, as quais representam a personificação do útero, ressaltando a fertilidade da mulher, e não necessariamente a representação materna. Os coreiros ${ }^{7}$ são a representação da força e virilidade, e é na comunicação entre coreira e coreiro que se dá o momento poético, simbólico e religioso, pois o tambor é a ponte de ligação entre o sagrado, o divino, e o profético entre os santos e os humanos. É nesse momento do batuque de umbigada que os brincantes repletos de "benquerença", depois de um dia de lida, aos céus agradecem, cumprem a missão e se realizam como gente diante dos olhos bondosos da sua crença.

A pesquisa teórica se deu por uma perspectiva dialética, Mito - História - Realidade, que envolveu conhecer a representação mitológica de São Benedito, como ele se incorporou na história da cultura afro-brasileira e como se dá essa relação nos dias de hoje na feitura da roda. Do mesmo modo, isso ocorreu na pesquisa prática, principalmente na construção dramatúrgica (literária, da cena, do corpo, da dança), na qual a tríplice se deu da seguinte

4. É um termo usado entre os praticantes do folguedo e quer dizer dançar, brincar, viver.

5. Punga é um termo específico do Tambor de Crioula, da umbigada dada entre as dançarinas, esta é realizada quando uma dançarina quer entrar na roda e tem que tirar a outra. A punga é dada no ritmo do tambor, há um momento certo dentro da cadência musical para ser realizada.

6. Coreira ou Crioula é o termo utilizado para denominar as dançarinas de Tambor de Crioula.

7. Coreiro ou Tambozeiro é o termo usado para denominar os homens tocadores dos tambores, feito de tronco de árvore e couro de boi. 
maneira: Ancestralidade - Matrizes - Cena Afro-brasileira. O contato com alguns saberes tradicionais advindos da história e da memória ancestral, pertencente à essência da manifestação, e o aprendizado das matrizes da dança e da organização, ressignificam esses aprendizados em cena, buscando a identidade da cena afro-brasileira. Querença se constitui na simbologia da manifestação trabalhada e nos reflexos que esta sugere nas correlações e coexistência do misterioso, divino e sagrado tão presentes na memória do imaginário popular brasileiro em diálogo com o espetacular. É a possibilidade de falar das atrocidades históricas ocorridas em solo brasileiro sob a perspectiva do que é positivo e das manifestações sagradas e profanas por meio da poética cênica. Querença traz em si uma potência simbólica, num tempo-espaço em que o corpo da atriz e a música percussiva comungam da tessitura de uma dramaturgia pautada na organicidade do tempo-(em)memória. A relação com São Benedito é o centro dessa trama, na qual se busca um espetáculo atingido pelas verdades do corpo, priorizando as questões da contemporaneidade do grupo social que retrata o corpo da mulher negra, a fé, a solidão, a festividade, o sagrado, os dramas e alegrias vividos no imaginário popular, não perdendo o foco fundamental do ser humano e de sua essência.

A importância do figurino em se ater à tradição do Tambor de Crioula é um posicionamento político. A mulher vestida de saia longa rodada estampada, anágua e adornos, que compõem a figura da coreira e sua significação dentro do contexto afro-brasileiro, faz referência aos ritos religiosos de matriz africana e ao quanto os adornos são representativos, cheios de elementos e significados que compõem a mitologia afro-brasileira, pautada na mitologia dos orixás e no homem vestido de calça comprida e camisa estampada. Os elementos que compõem os figurinos, como a saia bem rodada, a anágua, a blusa de renda, os colares, turbantes e camisas estampadas representam, junto com a personagem, a sua crença e a sua posição social diante a manifestação a que faz parte, já que são características resguardadas desde os tempos de escravizados. A saia é um elemento bastante importante dentro das danças populares, pois ela dá movimento, balanço e cor à dança, é um parceiro na performance da dançarina, pois a ajuda a criar movimentos para que cause o efeito da roda, do contínuo, princípio mitológico africano de grande importância nas organizações sociais que seguem esses saberes. 
É partindo desse pressuposto que se mantém no experimento cênico as saias longas e rodadas, de acordo com a tradição, pois, mais do que um adorno de composição de personagem, torna-se também um elemento de cena. A opção por utilizar tecidos de cores fortes e estampados dialoga para a plasticidade da obra e retrata bem o foco de pesquisa do espetáculo, que trata do imaginário popular brasileiro, gente simples, em um universo lírico, penoso e poético.

O terreiro é o espaço simbólico de trabalho, repleto de simbologia, significantes e significados acerca da religiosidade afro-brasileira e suas culturas. A terra é compreendida como transmissor de saber e de energia: é dela que nascem as plantas, a água, é para ela que se vão os mortos, é na terra que o corpo se equilibra, é para a terra que a gravidade empurra o corpo e este reluta para não ser derrubado. Por isso, a necessidade de um olhar para o corpo negro, afro-brasileiro. Aqui, o tambor é visto como elemento de representação e força de uma estética negra, sendo ele um elemento sagrado e histórico, e, por isso, não há neutralidade em se colocar um tambor em cena, por si só ele carrega séculos de memória, resistência em ecoar saberes ancestrais a quem possa e esteja disposto a ouvir. Há diversas maneiras de conversar com o batuque, seja pelo toque do tambor ou pela escuta deste, seja pela dança ou pelo seu entendimento antropológico, no qual todos esses elementos se somam e completam uma manifestação popular brasileira bem-feita. É do tambor que nasce a energia da realização do folguedo, dos sentidos e significados ritualísticos da dança, e é para ele que se reverencia o poder da dança de cada brincante, a apreciação e o respeito com o legado a que pertence, isso se dá ao mesmo tempo, numa conversa afinada e honesta, um depende do outro e eles não existem separados.

O teatro é o tempo do ator, que tem como criação a extensão de seus membros, ideias e emoções. O pesquisador-criador tem o desejo das possibilidades diversas de si próprio, é livre e autônomo sobre a arte que deseja fazer, de acordo com suas estéticas, políticas, e das urgências que necessita comunicar. O corpo feminino, a alma e a importância da mulher refletem, nessa vivência cênica, os anseios em tratar do assunto primordial da condição do papel da mulher negra retratada em cena, na cena, para a cena e pela cena. É o corpo feminino negro descoberto, explorado e afirmado em diálogo 
com o tom da cultura brasileira. Que corpo é esse que trabalha, samba, sente, pari a vida, vela a morte, lida com a marginalidade e tem o dever de ser/estar resiliente? São questões como essa que disparam a criação em cena e a pesquisa contínua que a emergência do existir artista suscita. Enquanto manifestação de arte negra - cena afro-brasileira - mais que nunca o teatro precisa cumprir o ritual de colocar as pessoas, olhos nos olhos, para compartilhar a vida em profundidade, é preciso soltar a voz e aniquilar o silenciamento que nos é submetido há séculos.

\section{Referências bibliográficas}

BOAL, A. O arco-íris do desejo: método Boal de teatro e terapia. Rio de Janeiro: Civilização Brasileira, 1996.

"Boal Exilado": entrevista com Augusto Boal. Caros Amigos, São Paulo, v. 4 , n. $48,2001$.

FREIRE, P. Pedagogia do oprimido. Rio de Janeiro: Paz e Terra, 1994.

MUNANGA, K.; GOMES, N. L. Para entender o negro no Brasil de hoje: história, realidades, problemas e caminhos. São Paulo: Global, 2004.

Recebido em 08/05/2017

Aprovado em 10/06/2017

Publicado em 05/09/2017 